\title{
A Case of van Neck-Odelberg Disease and Intermittent Overuse Injury
}

\author{
İlke BEYİTLER, Salih KAVUKCU \\ Department of Pediatrics, Near East University Hospital, Nicosia, Turkish Republic of Northern Cyprus
}

\begin{abstract}
In van Neck-Odelberg disease, an enlarged anatomical structure called ischiopubic synchondrosis is susceptible to mechanical stress which causes delayed ossification of this temporary joint. Features of the disease, particularly if unilateral, may mimic other conditions such as neoplasm, stress fracture, or osteomyelitis. In this article, we present a seven-year-old male patient with right painful ischiopubic synchondrosis which was misinterpreted as a subacute fracture of which its symptoms resolved with rest and analgesics. Three and six months later, he developed patellofemoral pain syndrome on the left leg due to overuse of that contralateral side. Clinicians should be careful when evaluating leg pain on the overused side opposite to ischiopubic synchondrosis.

Keywords: Arthralgia; ischiopubic synchondrosis; overuse; recurrent pain.
\end{abstract}

The van Neck-Odelberg disease is hyperostosis of ischiopubic synchondrosis (IPS). Synchondroses are temporary joints which appear during skeletal maturation. Bilateral widening of IPS is a normal growth entity, but if painful and unilateral, diagnosis becomes difficult. Symptoms are groin or buttock pain. Fever, elevation of C-reactive protein (CRP), and erythrocyte sedimentation rate (ESR) are absent. Negative blood culture with nonspecific radiography is also diagnostic., ${ }^{1,2}$

\section{CASE REPORT}

A seven-year-old male patient with left foot dominance presented to a medical center with severe acute right groin pain. There was no history of trauma. He could not bear weight on his right limb, pain was localized in the groin, radiating to the knee. He was unable to raise his leg and hip adductor muscles were very tender to touch.
Range of motion of right hip was very painful and restricted. Laboratory tests revealed slightly increased leukocytes with normal CRP and ESR. Anteroposterior radiographs of the pelvis showed enlarged right IPS characterized by focal areas of osteolysis (Figure 1). Hip magnetic resonance imaging (MRI) showed hypointense sclerotic corticomedullary discontinuity at anterior of right ramus pubis (Figure 2a) together with edema of perilesional soft tissue and muscles (Figure 2b). These findings were misinterpreted as a subacute fracture. The patient was recommended bed rest and analgesics and he recovered after three weeks. A written informed consent was obtained from the patient.

Three months later, he was referred to our hospital and admitted with pain and swelling at left knee and pain at left hip after a few days of sports activities at school. On physical examination; he had $37.8{ }^{\circ} \mathrm{C}$ fever, oropharyngeal hyperemia,

Received: March 16, 2016 Accepted: June 20, 2016 Published online: November 07, 2016

Correspondence: İlke Beyitler, MD. Yakın Doğu Üniversitesi Hastanesi, Çocuk Sağlığı ve Hastalıkları, 99138 Lefkoşa, KKTC.

Tel: +90 548 - 8542670 e-mail: ilkebeyit82@yahoo.com

@2016 Turkish League Against Rheumatism. All rights reserved. 


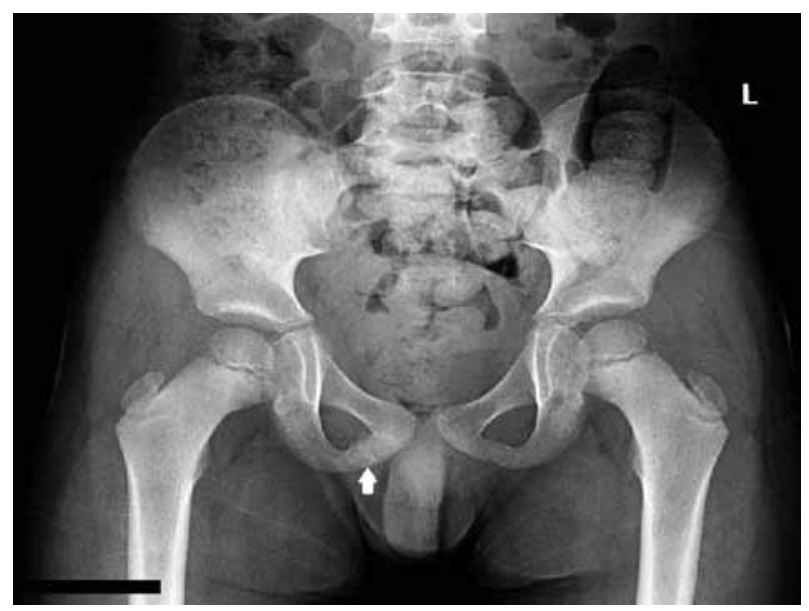

Figure 1. Anteroposterior pelvic radiograph showing enlarged ischiopubic synchondrosis.

swelling and local temperature increase on the knee, pain in knee joint, and pain in hip joint movements. Leukocyte count, ESR, CRP, rheumatoid factor, anti-streptolysin $\mathrm{O}$, and throat culture were normal. Knee MRI showed significant increase of intraarticular fluid and synovial hypertrophy. There were fluid in infrapatellar fat pad and suprapatellar bursa as well. The condition was evaluated as patellofemoral pain syndrome and upper respiratory tract infection after sports activity. Symptoms resolved with rest and nonsteroidal antiinflamatory drugs in four to five days.

After six months, he presented with severe pain at left thigh and knee. He had sports activities like football during the previous days. $\mathrm{He}$ could not raise his leg and hip movements were very painful and restricted. Leukocyte count and CRP were normal with ESR: $17 \mathrm{~mm} /$ hour. Pelvic ultrasound was normal. He was given nonsteroidal antiinflamatory drugs and symptoms disappeared in a few days. The patient was diagnosed again as patellofemoral pain syndrome.

\section{DISCUSSION}

Swelling at the ischiopubic fusion zone in prepubertal skeleton is now known to be a normal ossification pattern. Unbalanced mechanical stress, such as jumping or kicking, induces inflammation and delayed ossification. ${ }^{3,4}$ It may be misinterpreted as an infectious, traumatic or neoplastic condition. ${ }^{5}$

Ischiopubic synchondrosis may mimic other pathologies, especially stress fractures, posttraumatic osteolysis, osteomyelitis or bone tumors. Stress fractures occur after vigorous exercise or radiotherapy and differ from IPS in having bone marrow edema and irregular shaped MRI findings. Posttraumatic osteolysis results from trauma and includes irregularity or erosion of the affected side seen on MRI. Osteomyelitis of the ischiopubic region involves typical characteristics like fever, inflammation signs on the pelvis, elevated ESR and CRP, positive blood culture and abscess or fluid formation. Neoplastic conditions are different both with slower onset of complaints and radiological features such as lytic lesions with soft tissue involvement. These conditions should be considered in the differential diagnosis of IPS..$^{1-3}$
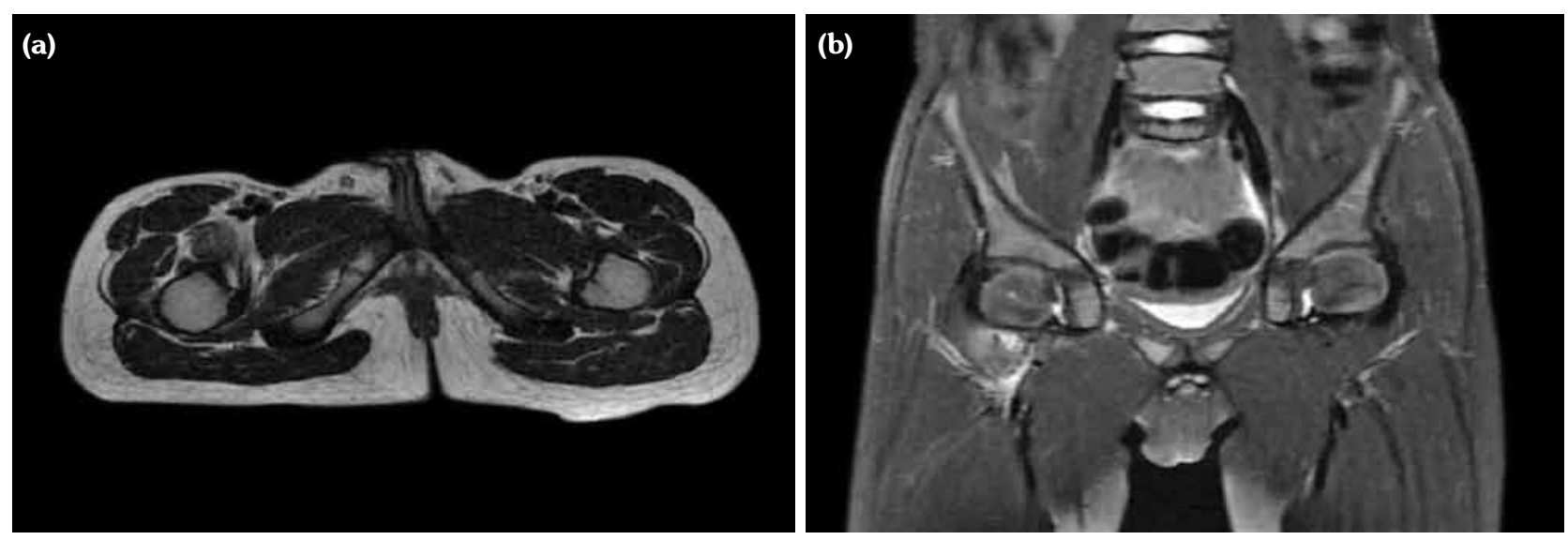

Figure 2. (a) Axial $T_{2}$ magnetic resonance image demonstrating ischiopubic synchondrosis enlargement with irregular edges and (b) coronal $\mathrm{T}_{2}$ magnetic resonance image showing perilesional edema. 
Ischiopubic synchondrosis was found to occur in $61 \%$ of a population. ${ }^{6}$ Fibrous bridging and fusiform swelling of adjacent soft tissue can be observed as well like the current case. ${ }^{6}$

Dominant swinging leg is used in skilled motor activities, whereas nondominant standing leg sustains major strain. In a cohort of Herneth et al., lesions were left sided in $78 \%$ of children with unilateral IPS. They overuse their left legs, so unequal distribution of mechanical forces causes delayed closure of IPS on left side in initial period. Later on, weight bearing leads to pain on IPS side; therefore, children begin to underuse that side and overuse the contralateral side. Afterwards, pain becomes more frequent on contralateral side. ${ }^{5}$

We determined that left leg was the dominant leg of our patient by asking his parents which leg their child used to kick a ball and by telling the child to kick a ball. In IPS cases, nondominant side is closed first and dominant side is closed afterwards due to gravity.

Our finding was delayed closure of this temporary joint due to strain and excessive weight bearing on nondominant extremity during vigorous exercise. In a study, IPS on nondominant side was closed first and dominant side closed later. ${ }^{5}$ However, our case was not compatible with that study. ${ }^{5}$ This may be due to the limited number of cases in the study. ${ }^{5}$ In our case, dominant leg was left side and IPS was at the right side.

In our case, initial presentation was right groin pain, but subsequent complaints were related with left hip and knee. This may be attributed to increasing efforts of dominant lower extremity in bearing body weight. During sports activities, the patient was underusing his lower extremity on the lesion side. Overuse injury of the left leg caused discomfort and musculoskeletal pain after exercise, manifesting as patellofemoral pain syndrome. The current case was distinct in having effusion in knee joint at first attack, which may be attributed to weight bearing. ${ }^{5,7}$

Patients with IPS may present with prominent complaints on contralateral side. Therefore, patients particularly giving a history of groin pain at other side may be directly diagnosed as IPS.

\section{Declaration of conflicting interests}

The authors declared no conflicts of interest with respect to the authorship and/or publication of this article.

\section{Funding}

The authors received no financial support for the research and/or authorship of this article.

\section{REFERENCES}

1. Wait A, Gaskill T, Sarwar Z, Busch M. Van neck disease: osteochondrosis of the ischiopubic synchondrosis. $\mathrm{J}$ Pediatr Orthop 2011;31:520-4.

2. Oliveira F. Differential diagnosis in painful ischiopubic synchondrosis (IPS): a case report. owa Orthop J 2010;30:195-200.

3. Macarini L, Lallo T, Milillo P, Muscarella S, Vinci R, Stoppino LP. Case report: Multimodality imaging of van Neck-Odelberg disease. Indian J Radiol Imaging 2011;21:107-10.

4. Asymmetric closure of ischiopubic synchondrosis in pediatric patients: correlation with foot dominance. MR imaging of the ischiopubic synchondrosis. Magn Reson Imaging 2000;18:519-24.

5. Herneth AM, Philipp MO, Pretterklieber ML, Balassy C, Winkelbauer FW, Beaulieu CF. Asymmetric closure of ischiopubic synchondrosis in pediatric patients: correlation with foot dominance. AJR Am J Roentgenol 2004;182:361-5.

6. Herneth AM, Trattnig S, Bader TR, Ba-Ssalamah A, Ponhold W, Wandl-Vergesslich K, et al. MR imaging of the ischiopubic synchondrosis. Magn Reson Imaging 2000;18:519-24.

7. LeBlanc $C$. Noninflammatory musculoskeletal pain. In: Petty R, editor. Textbook of Pediatric Rheumatology. Philadelphia: Elsevier; 2016. p. 666-80. 